\title{
Nas trilhas do Parque Estadual de Vila Velha, (Paraná- Brasil): entre formas e grafias da paisagem
}

\author{
On the trails of Vila Velha State Park (Paraná-Brasil): between \\ landscape shapes and lines
}

Danieli Barbosa de Araujo, Departamento de Geografia, Universidade Estadual de Londrina, Brasil, danieli_g5@hotmail.com

(1) https://orcid.org/0000-0002-9980-3393

Larissa Alves de Oliveira, Departamento de Geografia, Universidade Estadual de Londrina, Brasil, larissa-alvez@hotmail.com

(D) https://orcid.org/0000-0003-2918-7473

Denilson Manfrin Goes, Departamento de Geografia da Universidade Estadual de Londrina, Paraná, Brasil, denilsongoes@uol.com.br

(1) https://orcid.org/0000-0001-5658-9350

Resumo: Esta pesquisa discute o potencial pedagógico dos patrimônios geomorfológicos como espaços de formação cidadã, por se constituírem como locais acessíveis à construção e a difusão de conhecimentos nas diferentes fases educacionais. Neste sentido, como forma de usufruir das potencialidades formativas dos patrimônios geomorfológicos, propôs-se por meio de uma prática interdisciplinar entre Geografia e Arte, um estudo, in loco, no Parque Estadual de Vila Velha, no município de Ponta Grossa, Paraná, Brasil. O objetivo foi aprofundar os conhecimentos sobre formas de relevo e estrutura geológica da Terra, bem como, estimular o potencial artístico e criador dos estudantes, do sexto ano do ensino fundamental de um colégio em Londrina/Paraná, por meio da realização de vídeos e fotos. O Parque Estadual Vila Velha é constantemente visitado para este fim, visto que se trata de um sítio geológico, tombado como Patrimônio Histórico e Artístico Estadual em 1966. Como resultados, verificou-se como o parque, enquanto patrimônio geomorfológico, apresenta potencial para o desenvolvimento de atividades de educação ambiental. O trabalho proporcionou uma percepção frente aos problemas ambientais da contemporaneidade, assim como, a sensibilização dos sujeitos para a temática ambiental. Conclui-se que a realização de trabalhos de campo com escolares em locais de geoconservação reverbera em aprendizado para a vida, uma vez que coloca os estudantes numa experiência direta com os locais visitados.

Palavras-chave: Geomorfologia; Educação ambiental; Ensino; Meio Ambiente; Geografia; Interdisciplinaridade.

\begin{abstract}
This research discusses the pedagogical potential of geomorphological patrimony as space for citizenship generation, due to its constitution as a reachable local to build and spread knowledge through different educational stages. In this sense, as a way to enjoy such formative potentialities of geomorphological patrimonies, a study in loco was proposed by means of a interdisciplinary practice between Geography ad Arts, taking place in the Vila Velha State Park, city of Ponta Grossa, Paraná, Brazil. The objective was to deepen the knowing on landscape shapes and Earth's geological structure, as well as to stimulate the artistic and creative potential of sixth grade students from a Londrina/Paraná middle school through videos and pictures. Vila Velha State Park is constantly visited for this purpose, since it is a geological site recognized as Historical and Artistic State Patrimony since 1966. The field research allowed students to experience a peculiar landscape and comprehend the land dynamics and the transformations provoked by different agents. As result, it was found that Vila Velha State Park, has considerable potential to be used as site for developing educational activities. The field research provided a perception of current environmental and sensitizing subjects towards environmental thematic. As conclusion, field researches to geoconservation sites offered to schools bring lifetime learning to the students, duo to their direct experience with the visited places.
\end{abstract}


Keywords: Geomorphology; Environmental education; Teaching; Environment; Geography; Interdisciplinarity.

\section{Introdução}

Compreender o potencial dos patrimônios geomorfológicos para a formação cidadã é vislumbrar caminhos para a valorização do conhecimento de mundo, das experiências e vivências dos sujeitos. Por meio do trabalho de campo é possível oportunizar contatos mais intimistas com a natureza, reconhecer sua importância e necessidade de preservação. $O$ trabalho de campo é compreendido como atividade investigativa e exploratória que acontece fora do ambiente escolar. É uma atividade que, na maioria das vezes, é vista com bons olhos pela possibilidade de sair da rotina de sala de aula, também sendo um instrumento didático muito importante para o ensino de Geografia.

Certos das potencialidades formativas que são ofertadas pelos patrimônios geomorfológicos, o presente trabalho buscou experienciar, por meio do trabalho de campo, o patrimônio de Vila Velha, no estado do Paraná. A atividade se mostra relevante e de grande significado frente a uma era na qual as relações interpessoais e de contato com meio ambiente encontram-se cada vez mais fragilizadas. O mesmo reforça como práticas interdisciplinares podem contribuir com este retorno ao natural e como a natureza pode ser uma grande sala de aula, sendo possível trabalhar conceitos e assuntos que seriam explorados apenas por meio dos livros didáticos.

O trabalho divide-se em três partes. A primeira buscou realizar uma caracterização da área estudada, apresentando suas características geomorfológicas, seu processo de formação e transformação. A segunda parte do trabalho destina-se a apresentar as potencialidades formativas presentes nos patrimônios geomorfológicos, e a possibilidade de ambientação com a natureza ofertada por eles. Tal contato, independente do patrimônio geomorfológico, é uma oportunidade de colocar-se frente ao mundo, de aprender a partir das experiências. A terceira parte do trabalho destinase a apresentar os resultados obtidos com a visita ao Parque Estadual de Vila Velha, bem como a refletir a importância de práticas que criem elos com o ambiente natural, colocando o sujeito como responsável pela saúde e bem-estar do meio ambiente.

\section{Características geográficas da área de estudo}

\subsection{O Parque Estadual de Vila Velha}

O Parque Estadual de Vila Velha corresponde a um sítio geológico criado em 1953, tombado como Patrimônio Histórico e Artístico Estadual em 1966. Localiza-se no município de Ponta Grossa, Estado do Paraná, Brasil (Figura 1), nas seguintes coordenadas geográficas: $25^{\circ} 14^{\prime} 17^{\prime \prime}$ Sul e 50 0' 39" Oeste, altitude 917 metros. Com área superior a três mil hectares, a sua criação objetivou preservar formações rochosas esculpidas pela erosão eólica e pluvial nos grandes blocos de Arenito. Hoje é um importante ponto turístico da região, motivando inúmeros trabalhos de cunho ambiental. Por estar localizado no estado do Paraná, local de residência dos 
estudantes que participaram do presente trabalho e por apresentar grande potencial pedagógico, foi escolhido como local favorável à realização do trabalho de campo.

Além dos monumentos geológicos, o parque é composto por grandes poços denominados Furnas e lagoas formadas por águas subterrâneas.

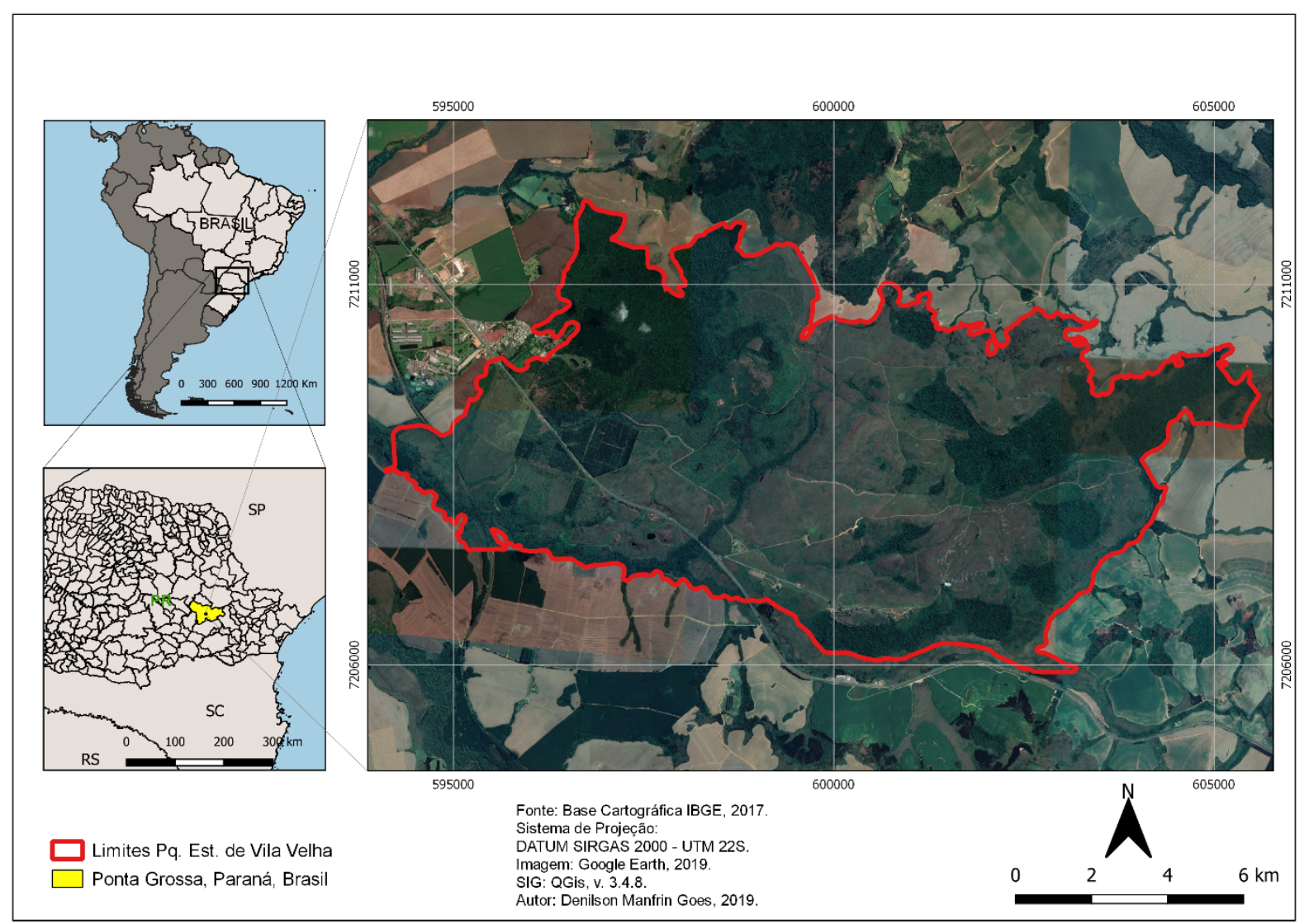

Figura 1: Mapa de localização da área de estudo

Org.: Denilson Manfrin Goes, 2019.

\subsection{Aspectos Geológicos}

Os monumentos geológicos encontrados em Vila Velha são constituídos por uma rocha denominada arenito, o Arenito Vila Velha, formado pela compactação e endurecimento de camadas sucessivas de areia, pertencentes à unidade geológica denominada Grupo Itararé. A formação destes arenitos remonta há 300 milhões de anos no Período Carbonífero, quando a América do Sul ainda estava ligada à África, à Antártida, à Oceania e à Índia, formando um grande continente chamado de Gondwana (Figura 2 e 3). Nesta época, a região onde se localiza Vila Velha estava mais próxima ao Polo Sul e a temperatura média na Terra era muito baixa, período que corresponde a uma das grandes eras glaciais do passado terrestre denominada glaciação gondwânica permo-carbonífera (Mineropar, 2019). 


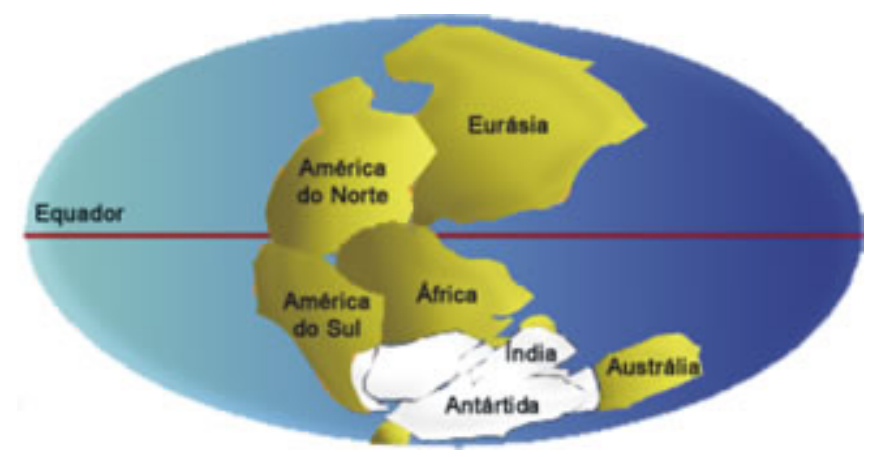

Figura 2: Carbonífero Superior / Permiano - 306 milhões de anos. Época de deposição das areias que formaram o Arenito Vila Velha. Esta região estava muito próxima ao Polo Sul, sendo recoberta por enormes massas de gelo, como hoje ocorrem na Antártida

Fonte: Mineropar, 2019.

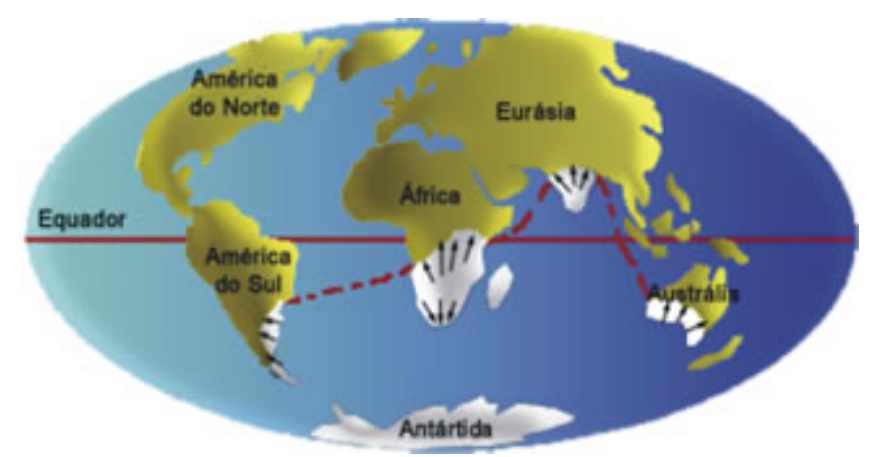

Figura 3: Hoje - Posição atual dos continentes. A distribuição das evidências geológicas da existência de geleiras a 300 milhões de anos. As setas indicam a direção de movimentação das geleiras

Fonte: Mineropar, 2019.

Quanto aos aspectos geológicos regionais (Figura 4), o Parque Estadual de Vila Velha localiza-se próximo à borda oriental da Bacia do Paraná, cerca de aproximadamente $10 \mathrm{~km}$ de distância a oeste do contato erosivo das unidades sedimentares paleozóicas sobre o embasamento proterozóico, aflorado a nordeste da área do parque. 0 grafismo geológico está representado pelas unidades da Bacia do Paraná, presentes na área estudada. São as formações Furnas e Ponta Grossa (Devoniano) e a base do Grupo Itararé (Carbonífero Superior). Estas unidades estão incluídas nas duas megassequências basais da Bacia do Paraná (Mineropar, 2019). 


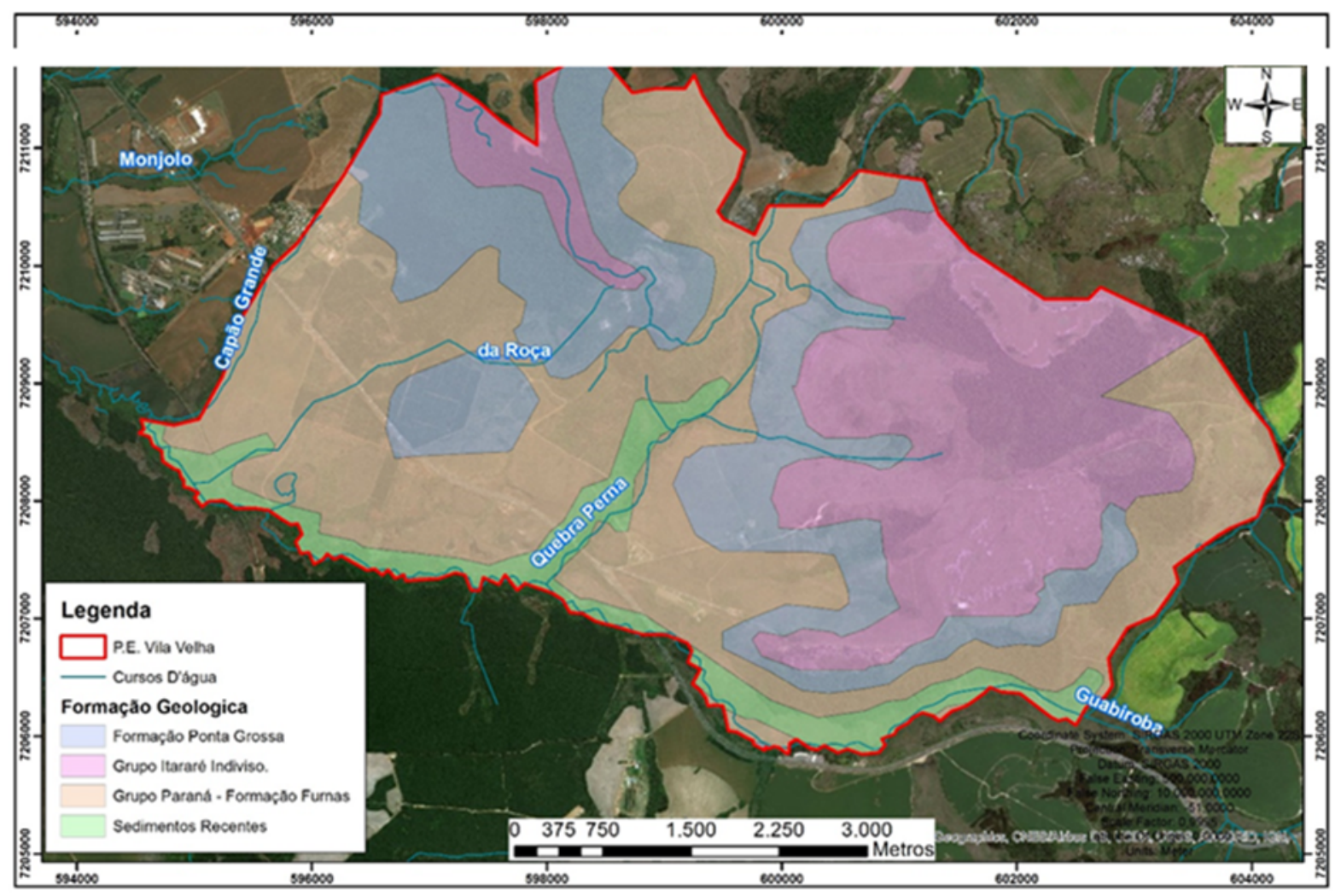

Figura 4: Geologia Parque Estadual Vila Velha

Org.: Vinícius Mello Iria, 2019.

\subsection{Os Arenitos}

Os monumentos geológicos de Vila Velha são constituídos por rochas areníticas, originadas a partir da compactação e endurecimento de camadas sucessivas de areia (Figura 5). "Os arenitos que compõem essas esculturas pertencem ao grupo Itararé, de idade carbonífera superior, ou seja, foram formados há aproximadamente 300 milhões de anos" (Antonello, Moura e Torres, 2005). Movimentos tectônicos terrestres aliados à erosão principalmente das águas pluviais, esculpiram o Arenito Vila Velha no Período Quaternário, ou seja, nos últimos 1,8 milhão de anos.

O domínio das geleiras, rios e lagos glaciais, formaram um ambiente denominado de flúvio-glacial. O movimento das geleiras para áreas mais baixas na fase de avanço, agregava em sua massa sedimentos rochosos encontrados pelo caminho. Rios e enxurradas, originados pelo próprio derretimento do gelo, levaram estes sedimentos, transportando e depositando as areias que formaram o Arenito Vila Velha. Marcas no substrato rochoso foram deixadas pelas geleiras, denominadas Estrias Glaciais. 


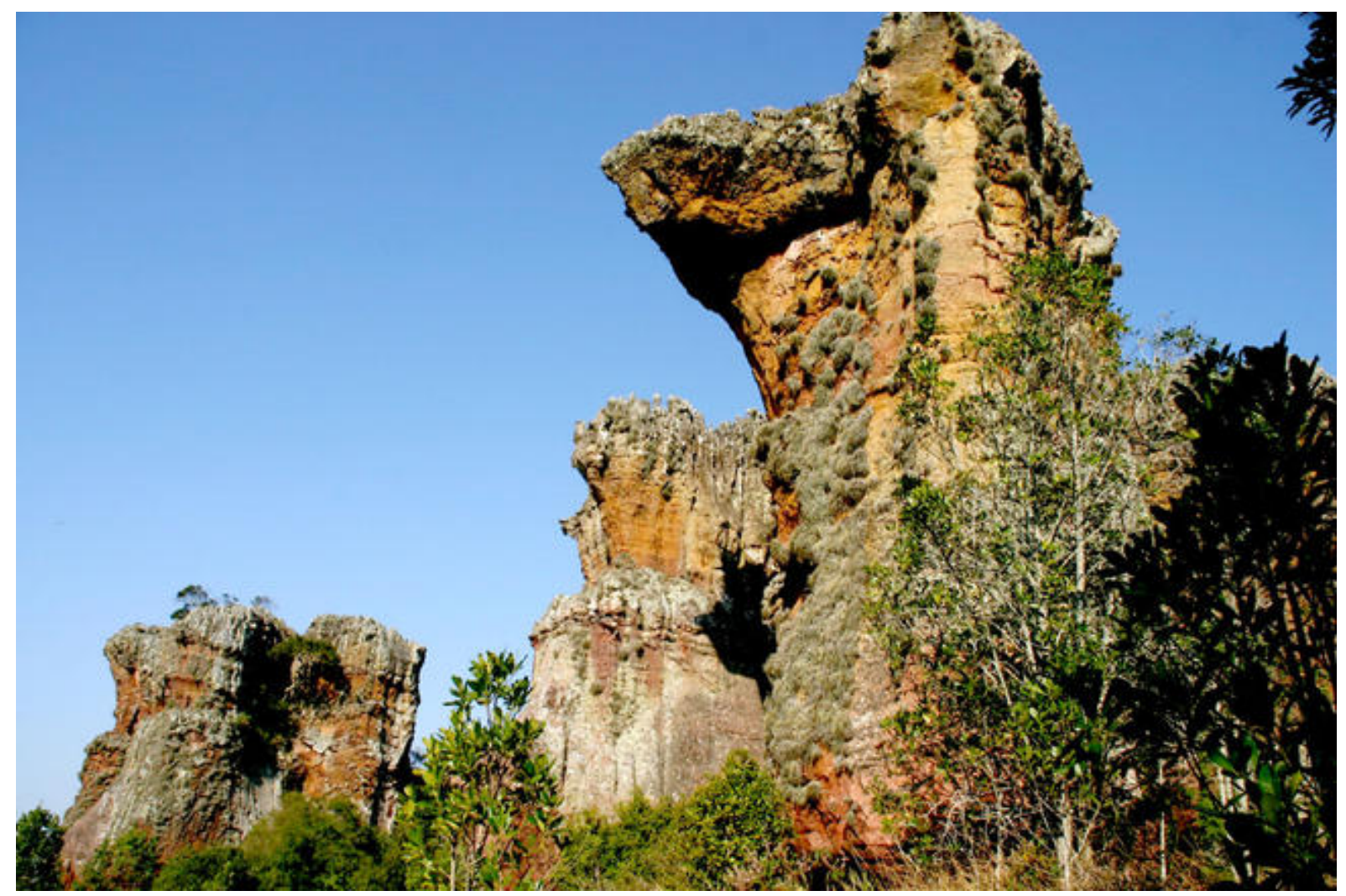

Figura 5: Formação de Arenitos em Vila Velha.

Fonte: Prefeitura municipal de Ponta Grossa, 2019.

\subsection{As Furnas}

As furnas são poços de desabamento em forma de crateras, de formato circular e paredes verticais. As furnas situam-se em uma unidade geológica que está abaixo do Arenito Vila Velha, representada pelos arenitos esbranquiçados da Formação Furnas (Figura 6).

As furnas se formaram pela ação da circulação das águas superficiais que, acidificadas pela presença de matéria orgânica, lentamente foram destruindo a ligação entre os grãos que mantém a rocha coesa, propiciando a remoção mecânica dos constituintes do arenito. Este processo é acelerado nas partes mais fraturadas do arenito, principalmente nas intersecções de falhas e fraturas, pontos em que a rocha vai sendo lentamente desagregada, possibilitando que seus constituintes sejam transportados pela drenagem subterrânea, formando os poços de desabamento.

A composição da vegetação natural e formações geológicas distribuídas na área do parque são potenciais para o desenvolvimento de atividades de Educação Ambiental. Os visitantes podem caminhar por trilhas interpretativas, contemplar a paisagem, observar espécies da fauna e da flora, fotografar a natureza e desenvolver pesquisas científicas. Destaca-se que, visando evitar processos erosivos, as trilhas encontramse calçadas em toda sua extensão. São pavimentadas com rochas que apresentam características similares às dos arenitos. Com isto, procura-se oferecer maior 
segurança ao visitante durante a caminhada e minimizar os impactos produzidos pelo uso público.

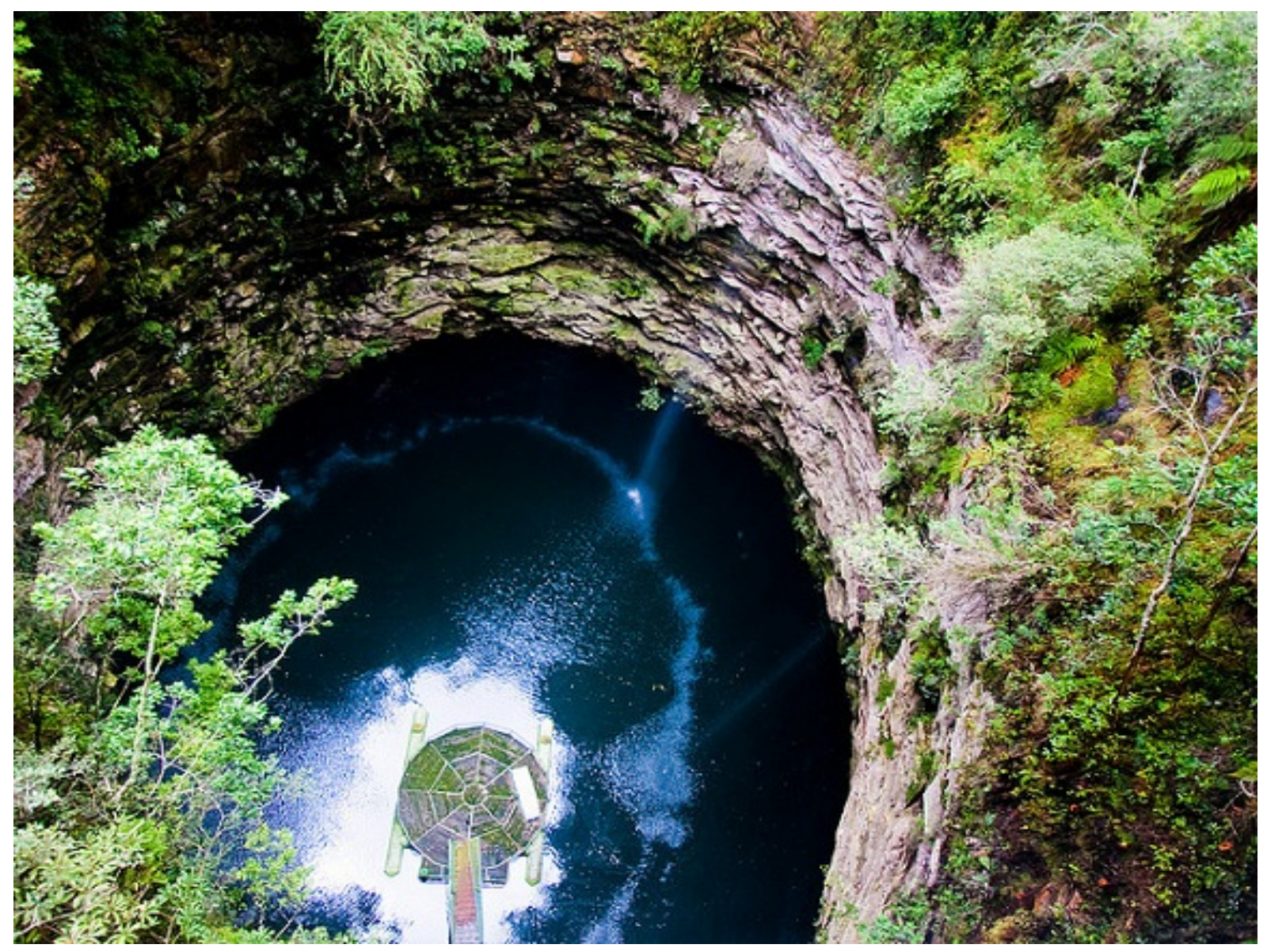

Figura 6: Formação geológica Furnas.

Fonte: Ludmila Saharovsky, 2019.

Durante o trabalho de campo realizado com os estudantes, descrito mais adiante, percorreu-se a trilha que dá acesso aos arenitos. No decorrer do trajeto foi possível contemplar as formações areníticas em suas diversas formas, as quais estimularam a imaginação, o interesse e a sensibilidade dos alunos.

\subsection{Os Solos}

Há ocorrência no Parque Estadual Vila Velha de três tipos de solos distintos (Figura 7), sendo predominante o Latossolo Vermelho Distrófico. Os Neossolos Litólicos Húmidos são encontrados em grande parte do lado leste do Parque, enquanto os Cambissolos Háplicos tb Distróficos estão em uma menor concentração em relação aos outros dois tipos de solos encontrados, na parte sudeste do Parque.

Os Latossolos Vermelhos Distróficos são solos minerais e possuem teores médios a altos de $\mathrm{Fe}_{2} \mathrm{O}_{3}$. Conhecidos anteriormente como Latossolos Vermelho-escuro, possuem textura argilosa e estão, na maioria das vezes, associados a relevo plano ou suavemente ondulado, o que favorece o seu uso para agricultura. 


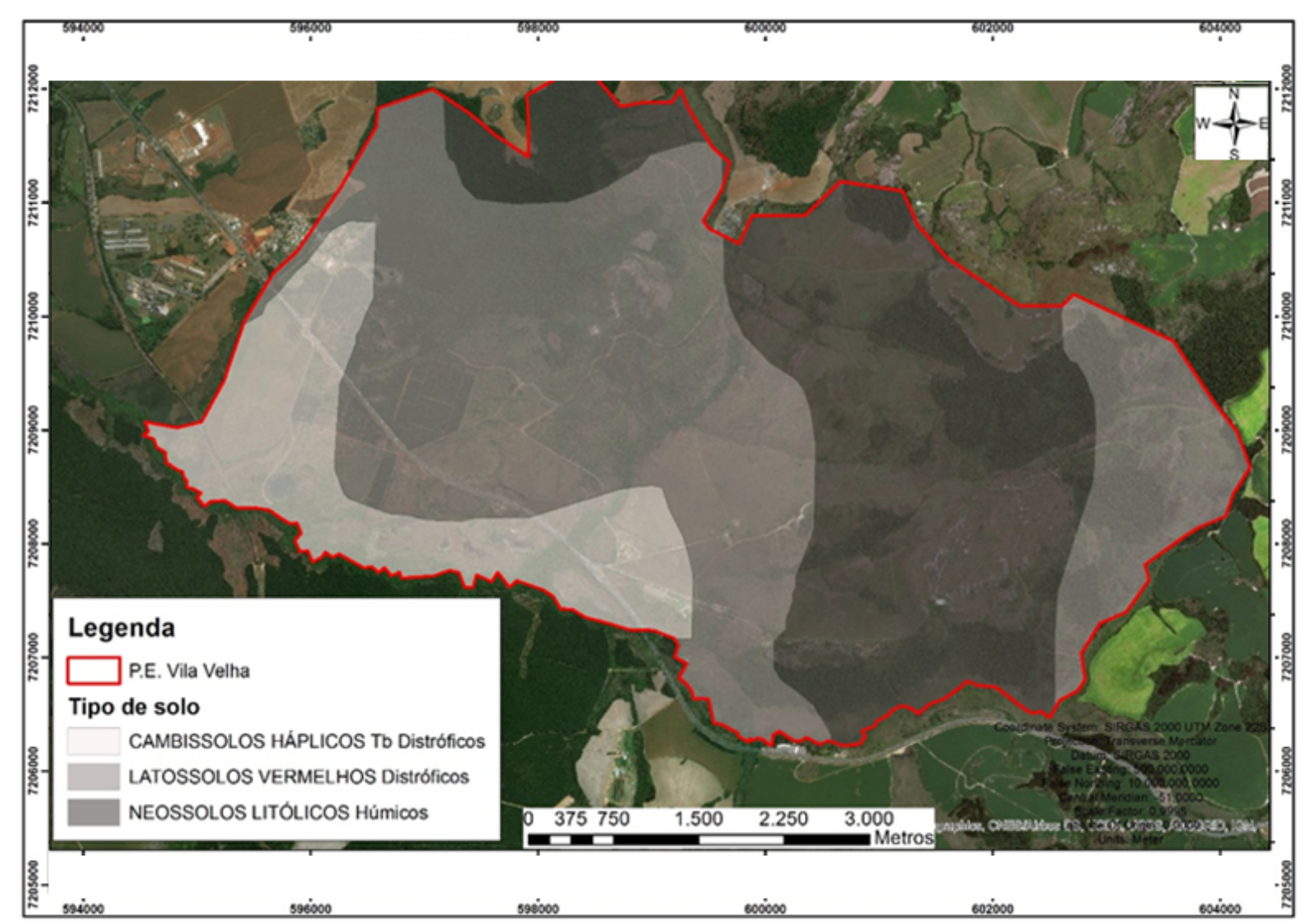

Figura 7: Pedologia Parque Estadual Vila Velha

Org.: Vinícius Mello Iria, 2019

Os Neossolos Litólicos Húmicos são solos rasos e com bastante presença de matéria orgânica, que não ultrapassam $50 \mathrm{~cm}$ de profundidade. Estão normalmente associados a relevos mais declivosos. Devido a essas características existem limitações para seu uso e são frequentemente indicados para preservação de fauna e flora.

Os Cambissolos Háplicos tb Distróficos são solos com argila de alta atividade e de baixa fertilidade, geralmente associados a relevos fortemente ondulados ou montanhosos, o que limita seu uso e os torna frequentemente enquadrados como área de preservação permanente pelo código florestal.

\section{Potencial pedagógico dos patrimônios geomorfológicos: espaço de formação cidadã}

Os patrimônios geomorfológicos, quaisquer que sejam, possuem grande potencial na formação cidadã. O contato corpóreo com tais espaços proporciona aos estudantes um vasto campo de aprendizagem, levando-os a questionamentos e reflexões, fazendo emergir competências necessárias ao exercício da cidadania, principalmente na esfera ambiental.

O trabalho de campo realizado no Parque Estadual de Vila Velha se apresenta como possibilidade de ambientação da natureza frente à realidade de muitos alunos da 
educação básica. Considerando que hoje, no Brasil, prevalece o meio urbano, com pequenas e médias cidades, estar no meio da natureza foge do cotidiano escolar. Esta fuga do ambiente escolar é capaz de proporcionar muitas experiências as quais podem ser caminhos para a construção de um conhecimento crítico de mundo, entendendo que conhecer o mundo é ato que permite ao homem uma experiência única, sendo tais experiências instintivas por meio da educação geográfica, aqui entendido como o conhecimento anterior até mesmo à cognição.

Para Dardel (2011) a Terra é mãe de tudo que tem vida, de tudo que é, havendo um laço de parentesco a tudo que cerca o Homem e, porquanto, "eles são o próprio Homem. É lá que ele se realiza e se conhece". Aprender coloca o sujeito diante de novas possibilidades de experiência e existência, e à medida que se aprende, novas dúvidas surgem, potencializando a ampliação do conhecimento em seu caráter existencial.

O conhecimento geográfico se reflete nesse pensar, ao compreender que o mundo é um lugar onde o sujeito está constantemente aprendendo, mesmo que este não se dê conta. Enquanto houver vida, haverá aprendizagem, o que significa dizer que o sujeito nunca para de aprender, visto que a aprendizagem é uma condição da existência.

Diante disso, a geografia escolar tem grande potencial de trabalhar as vivências atreladas aos conhecimentos científicos. Para Dardel (2011) "a geografia não implica somente no reconhecimento da realidade em sua materialidade, ela se conquista como técnica e irrealização". Desse modo, mesmo que de forma inconsciente o Homem produz uma geografia, uma geografia que vai além da materialidade cotidiana, mas está arraigada enquanto existência.

É necessário que a ciência geográfica trabalhe também com a compreensão de vivência, como única e singular e, portanto, em que cada sujeito contém um mundo, e cada mundo uma geografia pessoal e singular. Para Lowenthal (1982) cada indivíduo possui uma perspectiva de mundo e porque não uma geografia, pois cada indivíduo vive o mundo sob uma perspectiva. Para uma criança, por ter pouca idade e por consequência pouca vivência, o seu universo ainda é limitado àquilo que lhe foi visto e sendo seu círculo social ainda restrito, o mesmo há de considerar que tudo aquilo que the exprime importância faça sentido a partir de seu contato. Essa visão egocêntrica de mundo que compete à criança se molda com o decorrer dos anos. No entanto, para Lowenthal (1982) não importa quantos pontos em comum as crianças tenham de visão de mundo, para elas faltará uma visão compartilhada da natureza das coisas.

Essa visão compartilhada de mundo é pensada por Lowenthal (1982) através de uma metáfora em que "o mundo da experiência humana é, então, apenas uma árvore da floresta. A diferença é que o Homem sabe que sua árvore não é única, e ainda pode imaginar que a floresta, como um todo, possa ser semelhante", ou seja, o Homem a partir da experiência de mundo e até mesmo das convenções sociais passa a se moldar para compreender que há mundos parecidos com os seus e até mesmo a mudar seu próprio mundo para se encaixar nessa floresta do mundo compartilhado. 
Para Lowenthal (1982), enquanto indivíduos, acabamos aprendendo mais rapidamente a heterogeneidade do mundo nos atentando não somente a uma variável única, mas examinando superficialmente uma varidade de coisas, as quais somente nos salta aos olhos as que temos um interesse pessoal ou que nos ligue de algum modo sobre ela. Isto se aplica também ao que nos é ensinado, na medida em que aprendemos somente o que nos faça sentido. Dardel (2011) menciona que "antes do geógrafo e de sua preocupação com uma ciência exata, a história mostra uma geografia em ato, uma vontade intrépida de correr o mundo, de franquear os mares, de explorar os continentes". Seus escritos nos rememoram a essência da geografia enquanto ciência dos viventes, para tanto, levar essa essência para o ambiente de sala de aula é um desafio para o qual as metodologias, como o trabalho de campo podem contribuir.

O trabalho de campo em espaços naturais, como aqui realizado, proporciona vivências e experiências para além do ambiente escolar, colocando o indivíduo diante de outras realidades, proporcionando a ele reflexões que podem contribuir significativamente para seu processo de formação cidadã. Tal formação consiste em formar cidadãos responsáveis, críticos, ativos e intervenientes, capazes de intervir positivamente no ambiente escolar, na comunidade e na vida coletiva.

Para que o trabalho de campo seja eficaz em sua proposta, este deve ser precedido de uma discussão em sala de aula, envolvendo os alunos, para que os mesmos discutam a temática que será problematizada no trabalho de campo. Este estudo teórico prévio tem por objetivo um embasamento conceitual e metodológico que possibilitará a compreensão prática dos elementos físicos, socioambientais, culturais, etc. Para isso, o trabalho de campo usado como recurso educacional comumente passa por três etapas fundamentais, sendo: planejamento, realização e análise de observação do campo.

Com o trabalho de campo o aluno tem a possibilidade de observar a paisagem e identificar suas transformações no espaço tempo, a dinâmica ali envolvida e se perceber como parte e também produtor do espaço, contribuindo assim para sua formação cidadã. Para Callai et al. (1988) "estudar o município é importante e necessário para o aluno, na medida em que ele está desenvolvendo o processo de conhecimento e de crítica da realidade em que está vivendo". Desse modo, conhecer o Parque Estadual Vila Velha, sendo este tão próximo aos alunos paranaenses, que remonta a séculos, possibilita a compreensão dos impactos em escalas temporais. Para Resende (1989) "se o espaço não é encarado como algo em que o homem (o aluno) está inserido, natureza que ele próprio ajuda a moldar, a verdade geográfica do indivíduo se perde, e a geografia torna-se alheia a ele". Dessa maneira, é comum que os conteúdos de geografia se afastem da realidade dos alunos, em detrimento das vivencias dos mesmos, usam-se descrições impessoais que parecem distantes do mundo em que se vive, para tanto, o desafio é apresentar caminhos para a compreensão mais concreta e mais real do mundo. 
O Parque Estadual Vila Velha, por meio do trabalho de campo, mostrou-se como um espaço plural e formador. Estar em contato com tal ambiente levou os alunos a uma série de reflexões, como as interações espaço-tempo, a necessidade de preservação e conservação. Os traços históricos dos povos que ali habitavam, assim como em seu entorno também são detalhes marcantes na visitação. Tal patrimônio apresenta singularidades locais, costumes e inclusive demonstram o cuidado que a população tem com a sua história.

Os patrimônios geomorfológicos, de um modo geral, têm o potencial de ampliar a visão de mundo dos indivíduos, que associados aos conteúdos de sala de aula recontam a história e ressaltam a importância destes enquanto elementos fundamentais à percepção de ciência e mundo. Através da compreensão de que cada aluno possui experiências próprias, apresentar-lhes o patrimônio de Vila Velha demonstrou-lhes a grandiosidade do mundo e de como os mesmos, enquanto cidadãos, podem contribuir para a manutenção do espaço natural através da difusão de práticas sustentáveis.

\section{Nas trilhas de Vila Velha: um retorno à natureza}

Após a apresentação das características físicas do Parque Estadual de Vila Velha, bem como do potencial que os parques de conservação apresentam para o processo de formação cidadã, busca-se a seguir refletir sobre a importância de práticas que criem ligações com o meio ambiente, oportunizando um contato mais íntimo com o mesmo. Apresenta-se também o percurso metodológico utilizado na realização do trabalho de campo que dá origem ao presente artigo.

Sabe-se que a Educação Ambiental é um componente essencial no processo de formação do sujeito. Através dela é possível construir conhecimentos, valores sociais e atitudes voltadas para a conservação do meio ambiente. São imprescindíveis práticas pedagógicas que oportunizem o contato com a natureza, principalmente, em uma era na qual este contato encontra-se tão fragilizado.

A história humana sobre a Terra carrega em si marcas de um distanciamento gradativo entre homem e ambiente natural, uma dicotomia que foi sendo instaurada. Nossa memória de ligação com a Terra encontra-se em estado de vulnerabilidade e isso é reflexo do nosso distanciamento com o natural e do modo de vida imposto pelas cidades modernas.

Hoje, mais de $80 \%$ da população brasileira vive em centros urbanos. Muitas cidades, infelizmente, não têm priorizado espaços que ampliem a conexão dos sujeitos com a natureza. Muitas vezes as áreas verdes encontram-se em ambientes distantes, de difícil acesso, ou não raro, tornaram-se espaços de insegurança. Os olhares niilistas, comuns aos grandes centros urbanos, enfraquecem a capacidade de diálogo com o mundo, com o outro, com a natureza, promovendo uma apatia sensorial, um desencantamento. Até mesmo as funções básicas como caminhar ou sentar-se ao ar livre, passaram a ser cada vez menos privilegiadas. 
Perdemos a capacidade de nos envolver com os espaços, de senti-los, de nos familiarizarmos e de criarmos laços de intimidade. As crianças passam grande parte de seu tempo em ambientes fechados - dentro de casa, na escola, em frente às telas, em shoppings (Machado, 2018). Tais hábitos refletem-se em estilos de vida mais individualistas, sedentários, desfavorecendo o convívio social e a relação de afeto com o ambiente que as cercam.

A desconexão com o mundo natural, como sugere Machado (2018) empobrece o repertório da infância, reduzindo experiências e estímulos sensoriais, o que mais tarde influenciará na capacidade de auto regulação do sujeito, na aprendizagem, criatividade e no próprio processo de preservação do meio ambiente.

A criança em contato com a natureza torna-se o potencial cuidador e preservador do meio ambiente. Essa aproximação imprime registros no próprio corpo da criança, tais como o valor e a necessidade de cuidado com as árvores, rios e animais. A verdadeira educação ambiental se dá por meio do experienciar (Machado, 2018).

Os patrimônios geomorfológicos são importantes meios para explorar significados científicos, culturais e artísticos, assim como uma possibilidade de estimulo a corpografias com o ambiente natural. A visita ao parque Estadual de Vila Velha revelase como uma oportunidade de contato, um retorno a natureza, ainda que de forma parcial e ligeira (Figura 8). A escolha pelo Parque Estadual Vila Velha, como campo de estudo, justifica-se pelo seu vasto repertório didático, bem como pela sua localização, no estado do Paraná, local de residência dos estudantes.

A realização do trabalho de campo sucedeu uma abordagem teórica, realizada em sala de aula, nas disciplinas de Geografia e Arte. A primeira buscou seu enfoque nas formas de relevo, no tempo e na estrutura geológica da Terra, enquanto a segunda, incumbiu-se de analisar, sob uma perspectiva artística, as formas de relevo, seus contornos e traços. Buscou-se, também, estimular o potencial artístico e criador dos estudantes, por meio da realização de vídeos e fotos que mostrassem a importância da preservação, a beleza natural do Parque Estadual de Vila Velha, assim como suas percepções e sentimentos em relação à visita.

Além do conteúdo acadêmico que envolveu a realização da prática em campo, fomos movidos pela necessidade de estimular a Educação Ambiental através do contato dirigido com a natureza, oportunizando experiências sensitivas e intimistas. Dentro do percurso metodológico para a realização do trabalho, o mesmo consistiu em pesquisas e aulas prévias sobre as formas de relevo presente no parque, os tipos de rocha e seu processo de formação e degradação.

Ressaltou-se também os impactos ambientais decorrentes das atividades antrópicas e naturais. Em uma dinâmica interdisciplinar, ambas disciplinas, Arte e Geografia, buscaram mesclar seus conhecimentos criando aproximações entre si, a fim de refletir, para além dos conteúdos acadêmicos, sobre a necessidade de contato com o meio ambiente e a importância dos patrimônios geomorfológicos para tal contato. 


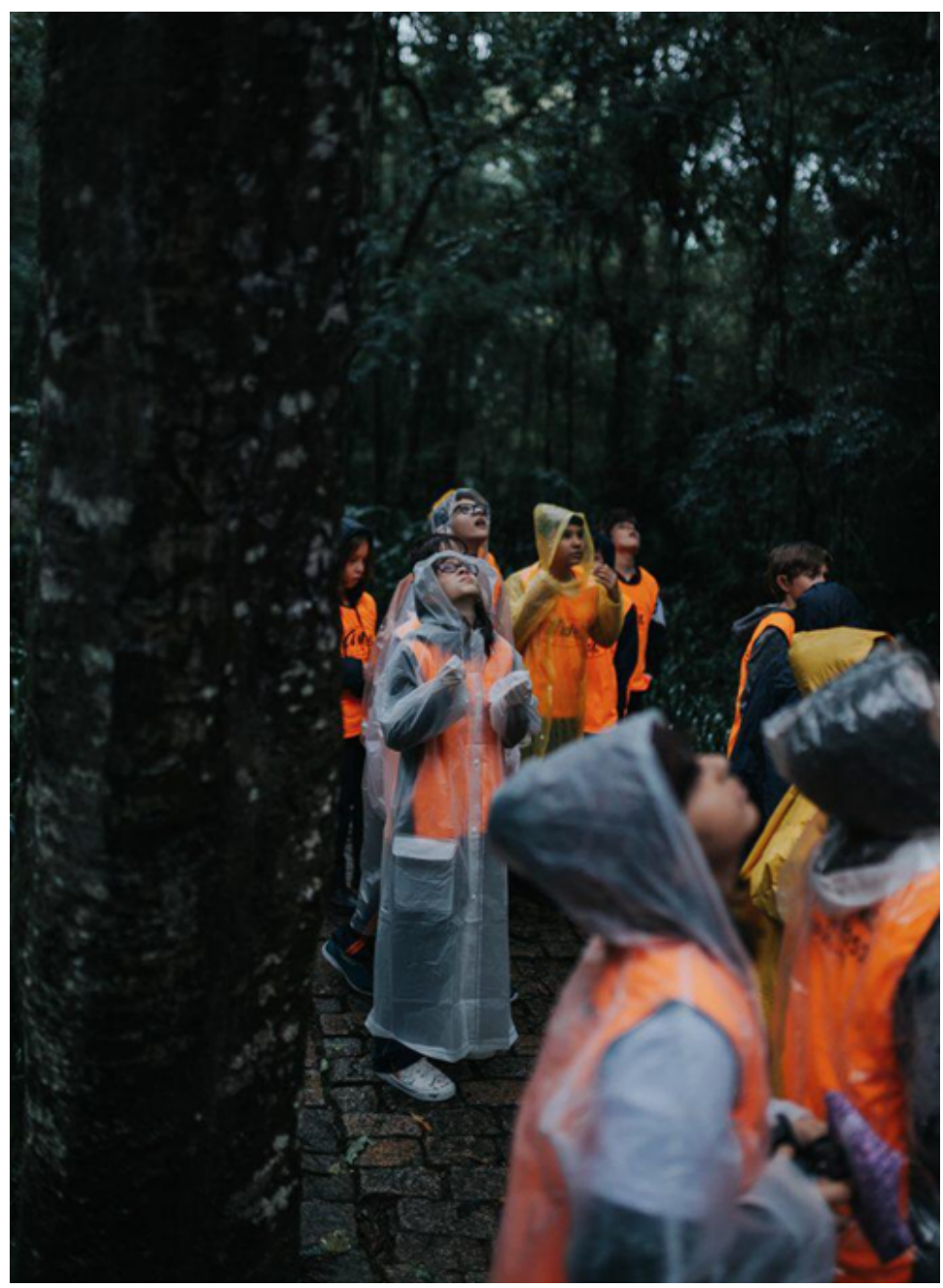

Figura 8: Trilhas interpretativas

Fonte: Danieli de Araujo, 2019.

Após as pesquisas realizadas em sala de aula, os alunos se puseram em contato direto com o local de estudo, e puderam experienciar na prática os conhecimentos adquiridos no ambiente escolar. No dia da visita, o grupo de cerca de trinta estudantes do sexto ano do ensino fundamental, acompanhados de seus professores e guia, percorrem a trilha que leva aos arenitos (Figura 9). A visita, seguida de pausas e explicações, tem duração aproximada de $1 \mathrm{~h} 30 \mathrm{~m}$. Os passeios são promovidos pelo Instituto Ambiental do Paraná (IAP) em conjunto com guias e condutores de ecoturismo.

Durante a trilha os alunos puderam contemplar as formas de relevo e, na medida em que caminhavam, as nomeavam de acordo com seu imaginário. O processo de esculturação conferiu às formas de relevo distintos nomes, como taça, elefante, índio, entre outras. Após concluir a visita guiada, os alunos puseram-se a percorrer o parque, usufruindo do tempo livre para se conectar com o ambiente, fazer registros, vídeos e expressar suas percepções sobre a visita (Figura 9). 

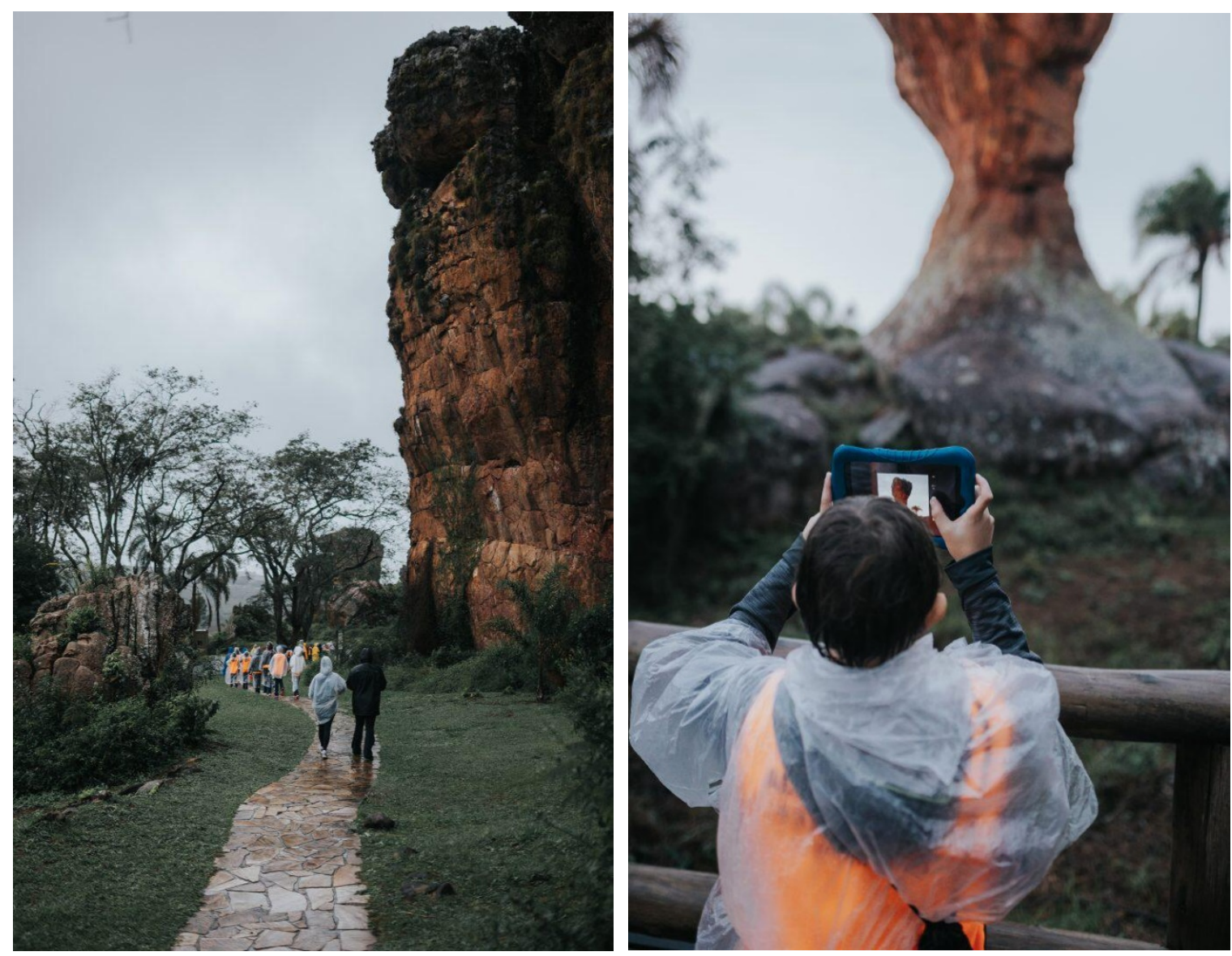

Figura 9: Trilha dos Arenitos e registros fotográficos.

Fonte: Danieli de Araujo, 2019.

Em sala de aula os professores puderam retomar o diálogo, analisar as fotografias e vídeos e dialogar com os alunos a respeito do trabalho de campo. Nos registros e depoimentos feitos pelos estudantes, muitos elucidaram o encantamento com a beleza natural do parque, assim como demostraram grande admiração pelas esculturas naturais oriundas de processos intempéricos. Temas como a necessidade de preservação e de práticas sustentáveis foram abordados pelos participantes.

Nota-se que práticas ativas que envolvam a participação dos alunos com o ambiente estudado otimizam o processo de ensino e aprendizagem. A realização do trabalho de campo transcendeu os conteúdos programáticos a serem estudados durante a atividade de campo. A mesma promoveu uma experiência singular de contato com a natureza. Expor-se à chuva, à lama, ao frio. Sentir o cheiro da vegetação e da terra, deixaram marcas memoráveis. 


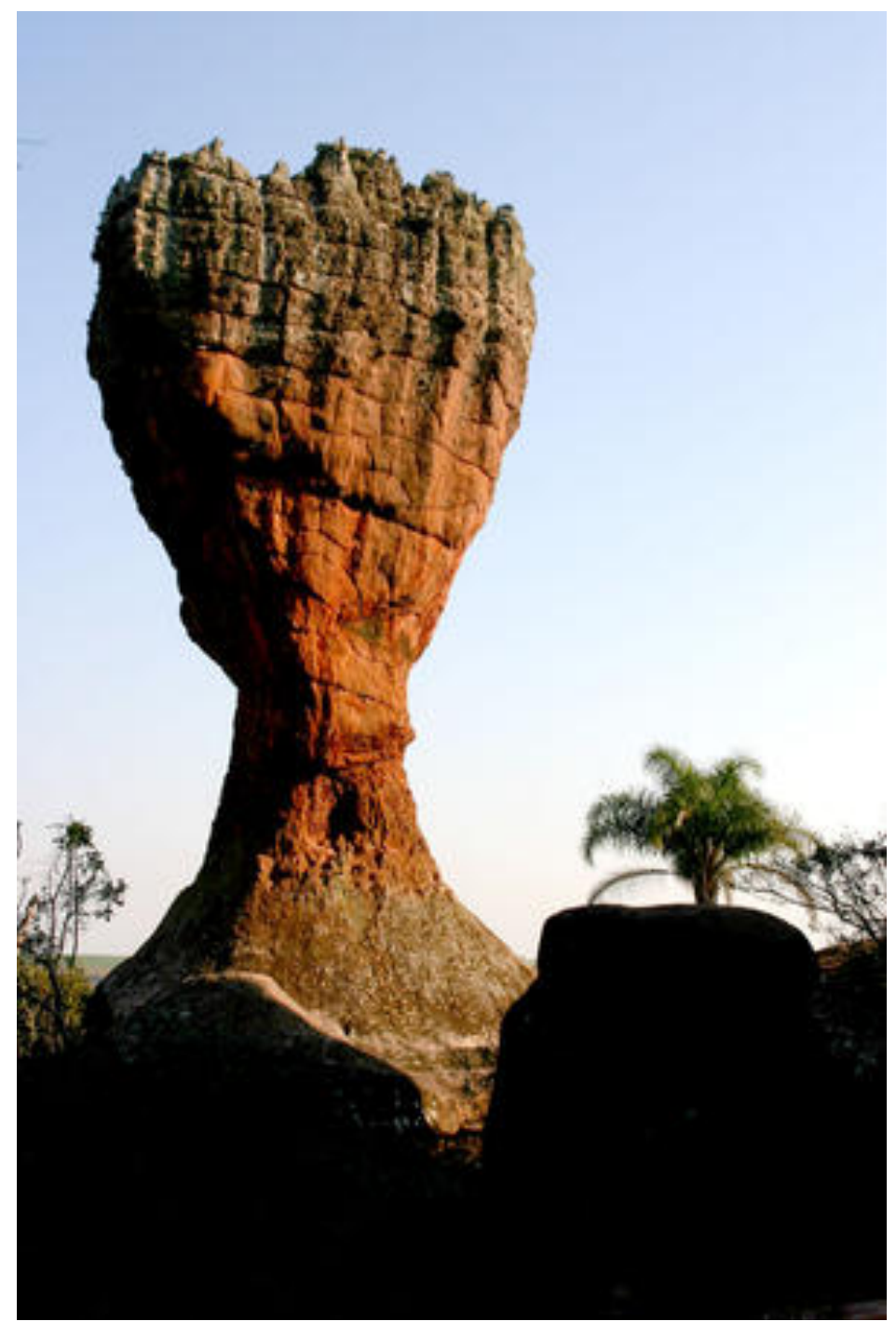

Figura 10: "Taça" escultura natural em arenito

Fonte: Prefeitura de Ponta Grossa, 2019.

\section{Conclusões}

Esta pesquisa teve como escopo abordar o potencial pedagógico dos patrimônios geomorfológicos como espaços de formação cidadã, por se constituírem como locais acessíveis à construção e a difusão de conhecimentos nas diferentes fases educacionais. Neste sentido, como forma de usufruir das potencialidades formativas dos patrimônios geomorfológicos, buscou-se, por meio de uma prática interdisciplinar entre Geografia e Arte, um estudo, in loco, no Parque Estadual de Vila Velha, no município de Ponta Grossa, Paraná, Brasil. O objetivo foi aprofundar os conhecimentos sobre formas de relevo e estrutura geológica da Terra, bem como estimular o potencial artístico e criador dos estudantes, do sexto ano do ensino fundamental de um colégio da cidade de Londrina, Paraná, Brasil, por meio da realização de imagens por vídeos e fotos.

O Parque Estadual Vila Velha tem grande potencialidade para recepção de turistas e para recepção de alunos da educação básica, contando inclusive com infraestrutura 
relevante. No entanto, para além desses aspectos, o parque é um patrimônio por contar parte da história paranaense e brasileira.

Os aspectos físicos do parque são extremamente relevantes, pois apresentam peculiaridades que, por vezes abstratas no imaginário dos alunos, saltam aos olhos com elementos ali presentes, como por exemplo a escultura em arenito denominada "taça". O uso de atividades para registro como fotografias e vídeos proporcionam uma visão mais atenta e estimulante aos seus jovens observadores.

O trabalho de campo enquanto metodologia é eficaz, na medida em que propicia novos conhecimentos sobre o mundo, mesmo que de fenômenos relativamente próximos fisicamente, como no campo descrito neste ensaio. A interdisciplinaridade neste sentido foi essencial para um olhar mais atento aos aspectos que compõem a paisagem ali apresentada.

Para além de componentes curriculares, a formação crítica dos sujeitos requer a compreensão das singularidades dos mesmos, mas o entendimento do mundo que nos rodeia. Para tal as experiências em novos espaços é fundamental, assim como um estudo posterior sobre o que foi vivenciado.

A sala de aula pode se tornar uma importante extensão do campo realizado à medida em que as vivencias proporcionam debates frutíferos e apreensão do mundo em que compartilhamos, bem como o avanço da ciência geográfica.

\section{Agradecimentos}

Agradecemos ao Programa de Pós-Graduação em Geografia, da Universidade Estadual de Londrina/UEL, Londrina, Paraná - Brasil e as Fundações Capes/Governo Federal e Araucária pelo auxílio financeiro.

\section{Bibliografia}

Antonello, I. T., Moura, J. D., Torres, E. C. (2005). Uma proposta para a formação de professores de geografia: trabalho de campo integrado. Revista Geografia. v.30, n.3.

Callai, H. C., Zarth, P. A. (1988). O estudo do municipio e o ensino de historia e geografia. UNIJUI.

Machado, A. L. (2019.) Movimento de retorno a natureza. Consultado em outubro 8, 2018, em: https://ciclovivo.com.br/vida-sustentavel/equilibrio/movimento-natureza-projetoeducacional/

Melo, M. S. D., Godoy, L. C., Meneguzzo, P. M., Silva, D. J. P. D. (2004). A geologia no plano de manejo do Parque Estadual de Vila Velha, PR.

Mineropar Minerais do Paraná S.A. (2019). Parque Estadual de Vila Velha. Consultado em maio 6,2019, em:

http://www.mineropar.pr.gov.br/modules/conteudo/conteudo.php?conteudo=14

Prefeitura Municipal de Ponta Grossa (2019). Parque Estadual de Vila Velha. Consultado em maio 2,2019 em: http://www. pontagrossa.pr.gov.br/parque-estadual-vila-velha. 
Nas trilhas do Parque Estadual de Vila Velha, (Paraná-Brasil): entre formas e grafias da paisagem Geoconservação e património natural

Resende, Márcia M. S. (1989). O saber do aluno e o ensino de geografia. In: Vesentini, J. W.(org) et. al. Geografia e Ensino: textos críticos. $5^{a}$ edição Campinas: Papirus.

Santos, H. G. dos; Zaroni, M. J; Almeida, E. P. C. (2019). Neossolos Litólicos. Agência Embrapa de Informação Tecnológica. Consultado em julho 29, 2019, em https://www.agencia.cnptia.embrapa.br/gestor/solos tropicais/arvore/CONT000gn230xho 02wx5ok0liq1mqxhk6vk7.html

Artigo recebido em/ Received on: 15/11/2019

Artigo aceite para publicação em/ Accepted for publication on: 27/03/2020

Nota: este trabalho baseou-se na apresentação efetuada no III Encontro Luso-Brasileiro de Património Geomorfológico e Geoconservação e selecionada para publicação na Physis Terrae. 
D. Araújo et al. / Physis Terrae, Vol. 2, n 1, 2020, 1-18

Página intencionalmente deixada em branco 